\title{
Selection versus Education: Editorial Introduction
}

\section{John Oxenham}

Why is educational reform so difficult to achieve in developing countries? ${ }^{1}$ In particular, why do programmes of vocational education or attempts to make education relevant to the kinds of lives which the majority of pupils will have to lead, meet with such depressingly small success? Margaret Sinclair and Kevin Lillis [forthcoming] have catalogued projects, ambitiously announced, which have simply dwindled to a few faithful and obscure centres. Their list ends in the mid-1960s. In 1966, the Kericho Conference in Kenya produced the idea of village polytechnics to train young school leavers for self employment. By 1978 , the polytechnics numbered 220 with an estimated enrolment of 22,000 students. But the graduates from the primary schools of that year numbered just over 280,000 , while the new enrolments in the general secondary schools for 1979 numbered around 110,000 . Village polytechnics have evidently not taken Kenya by storm. Again in the middle 1960s, Patrick van Rensburg began his production brigades in Botswana. His idea seems so sound, that the puzzle is why it has not been adopted more widely and why, even in Botswana, it still relies so heavily on expatriates.

Tanzania's programme of education for self reliance opened almost simultaneously: schools were to become production units and excellence was to be judged on moral and practical, not solely academic, grounds. A recent report [ILO 1977] intimates that production is still well below hopes and that the criteria of moral and practical excellence are so applied that only academic excellence is of importance. In western Africa, Ghana in 1969 opened a pilot project in continuation schools. Pupils in the last stages of the $\mathbf{1 0}$ year course in elementary education were to receive instruction in local crafts from local craftsmen. The programme is now nationwidebut not yet universal. However, a longitudinal study of its graduates, [Boakye 1977 and forthcoming], suggests that they differ not at all in orientation and fate from the graduates of the ordinary school.

China began its Cultural Revolution in 1966. Part of its effect was to change the schools. As in

1 No claim is made that educational reform is any easier in industrialised countries. It so happens that the focus here is on developing ones.
Tanzania, production and moral excellence were to be the touchstones of scholastic success. By the end of the $1970 \mathrm{~s}$, the process had gone into reverse-Jonathan Unger gives in this Bulletin some idea of the reasons why. In 1972, Sri Lanka embarked upon a novel scheme of pre-vocational studies for secondary schools. The idea, as in Ghana, was to connect schools with the livelihoods actually practised in their neighbourhoods. But the Ceylonese went further and tried to connect success in pre-vocational studies with general scholastic success. Reports suggested a burgeoning and an acceptance beyond expectation. Yet a change of government in 1977 brought the scheme virtually to an end.

On Latin America, Nigel Brooke discusses in this issue why the reforms for primary education in Mexico seem not to have taken hold. Elsewhere, Beatrice Avalos has given an obliquely cheerless impression of the Peruvian reforms, [Avalos 1977]. More generally, the World Bank seems to be retreating from projects in diversified secondary education. In short, educational reform and educational 'relevance' continue to this day to be beset by difficulty and uncertainty. The observation is as true of socialist countries, whatever the mix of their socialism, as it is of mixed economy and capitalist countries. So the source of difficulty appears not to lie in the political system.

Whatever their political differences, the socialists, mixers and capitalists among the developing countries do share four characteristics, which might help explain their problems with educational reform. One is a relatively weak system of schools with a high proportion of poor schooling. The lack of well trained, well paid, committed teachers compounds the lack of adequate texts, aids and equipment to make the path of reform slow and unpredictable. The other three common features need to be seen as a package, for they act in concert. They are: the stark differences between the incomes and comforts of traditional livelihoods and those of the growing modern sectors; the acceptance that everyone no longer has to keep his place but is, on the contrary entitled to try to promote himself from the traditional to the modern sector; and, finally, the practices, first, of restricting such promotion 
almost exclusively to people who have had a good deal of schooling and, secondly, of making the size of the promotion depend on the quantity of schooling successfully achieved. The last two factors rest, of course, on a belief again common across the political spectrum: namely, that different doses of schooling are the best way of producing for the modern sector the low, middle and high level manpower it requires.

Most reforms have concentrated on working inside the schools and have tried to ignore the second set of factors. Some-Tanzania's and Sri Lanka's, for instance-have recognised the force of the latter and have tried to grapple with them. Only China has tried to free itself from dependence on learning in the school and university-but has felt forced to reverse these tactics.

That turnabout had not happened, however, when the research introduced by this Bulletin was conceived. At that time, late 1972, China seemed to be alone both in thinking that the chief obstacle to 'relevance' in education might be the link between school and modern jobs, and in being determined to do something about it. What, after all, was the use of preaching 'relevance', scientific curiosity, creative thinking to solve problems, the dignity of practical skills and labour, when none of these things counted in selection for further education and qualification for better jobs?

It was a compelling lead to take up, for the ILO Employment Missions to Sri Lanka (1971) and Kenya (1972) had underlined how the selective and qualifying functions of the school and university submerged their educational purposes. A large reason for having the Missions in the first place had been the alarming growth of "educated unemployment'. They suggested that precisely because the schools were used to select manpower, their processes seemed actually to suffocate the qualities most needed in educated people -initiative, creativity, the capacity and will to be 'prime movers of development'.

Also by making people eligible for selectiontut not guaranteeing it-the schools were fuelling hopes and expectations which could not be fulfilled, but which would nevertheless keep people hanging about on the off-chance that a salaried job might turn up.

Worse, educational expenditures appeared to be distorted. Governments agree that sound elementary education is a basic human right of every citizen. Yet, well before every citizen actually gets an opportunity for such education, dispro- portionate sums of money are channelled to the secondary and tertiary schooling of small minorities. If the result of such allocations were more productive citizens who compensated the majorities for their deprivation, well and good. But too often the most obvious results are the enlargement of both educated unemployment and bureaucracies manned by workers reluctant to work.

The IDS response to these stimuli was to embark on a research project, 'Qualification and Selection in Educational Systems'. There were a number of objectives. A primary one was to examine the justifications for using scholastic attainments to ration access to modern jobs. Governments and other employers maintain schedules of correspondence between jobs, salaries and schooling. If their reasons for so doing are good, the bad effects just enumerated might simply have to be lumped as unintended but necessary evils, part of the costs of development. If their reasons are poor, the way would be open to press for alternative ways to prepare and select people for modern jobs, without damaging education. Whatever their answers, knowing what they thought they got out of the system would help guide reform. For we would know what functions would have to be met in order for a new system to be acceptable to employers. The first article below looks at a number of employers-government and private -in three countries. Their rationales for linking jobs, pay and education were scarcely good. Indeed it seemed that many large employers were more than a little slipshod in their thinking and practices for recruitment and selection. Further, they seemed unaware of any wider social responsibility or of any effects they might be having on the demand for and the processes of education. Their immediate convenience was their main preoccupation.

Expecting some assertion that more educated workers were better workers, the enquiry followed the question of education and productivity to the shop and office floor: were more educated workers and managers in fact any more productive than their less educated colleagues? Angela Little's analysis of the information from three countries yields an answer heavy with doubt.

But even if employers cannot give good answers, and even if higher education is no predictor of higher productivity, does the quest for qualifications really have bad effects on education? Answering this question was an equally important objective. Little's second article does suggest that young people in school do have their hopes fixed on modern, nonmanual employment. Unger 
asserts the same for China. Nigel Brooke confirms that this is probably the case in Ghana, but is a good deal less certain in some of the rural schools of Mexico. Do such hopes affect the content and process of learning? The verdicts of Unger, Brooke and Keith Lewin all support this conclusion, but the emphasis differs between countries.

In Malaysia, apparently, the pupils and teachers work in alliance to satisfy the central Examinations Syndicate, rather than the aims of good science education. A similar, but milder, alliance operates in the middle schools of Ghana. In China, the teachers apparently wanted to work for the aims of good education but had to put up with rebellion from the pupils, for whom good education led only to the countryside, which did not need any education anyway. In Mexico, by contrast, many pupils and parents in the rural state of Michoacan wanted education for its own sake, but the reforms to achieve 'local relevance' were subverted by the teachers. They felt that the official definition of 'relevance' was in fact unrelated to modern life in the city, which in their view was the proper goal of schooling. In any case, they also felt unequipped to implement the reforms.

The importance of the attitude of the Michoacan teachers lies in this: unlike their confrères in Malaysia and Ghana, they are not constrained by a system of centralised examinations. They themselves assess whether or not a pupil should graduate, and they are subject to very little supervision or interference from their superiors or inspectors. Indeed, they are for all practical purposes free to teach as they fancy. Their fancies by and large do not include scientific curiosity, problem solving or creative thinking-which are what the textbooks recommend-because they really do not believe these are necessary for modern life. Along with this view goes a certain impatience - if not contempt - with those parents and pupils who have no desire to move to city jobs. In other words, in Michoacan, the school system is not unable to cope with reform, but actively opposes it, on the grounds that promotion to the modern sector should be the goal of all students and that the criteria for such promotion should be the main concern of the school. One way or another, then, what modern employers are thought to want, does get in the way of educational reform.

However, such a bold answer is not enough. The very first Employment Mission-to Colombia -had offered what appeared an attractive solu- tion to rural-urban migration and intense rural pressure for modern sector jobs. Make agriculture profitable; make the villages decent places to live in, so that people have credible alternatives to the city and modern sector. Testing this prescription was the inspiration for the second major part of this research. If traditional livelihoods yielded incomes of a volume and stability comparable to modern ones, would parents and pupils (and even teachers, perhaps) be more concerned with good education and less bothered about good certificates? The evidence from Mexico seemed positive, but was confounded by other factors. Families of potters and furniture-makers were indeed not anxious for their children to leave the family and community for salaried work. But these same families were from minority ethnic groups, who were convinced that modern employers discriminated against them and who had therefore ceased looking for salaried employment. Further, exactly how much education was thought good and sufficient seemed to depend on the family occupation: potters' children seemed to need less before joining the pottery, than the children of furniture-makers, before they joined the family workshop. The potential economic contribution of children to family livelihood thus appears a more weighty consideration than the value put upon education.

This observation was associated with another: families which required education for its own sake seemed to need much less of it than families who wanted education for entry to the modern sector.

What these observations collectively suggest is that:

- a family's demand for education for its own sake or for basic literacy and numeracy is determined by its need for labour and by its children's capacity to contribute to the family's welfare;

-alternative sources of income will reduce the desire to enter the modern sector and hence also the demand for further schooling;

-blocks on movement into the modern sector will reduce the demand for further schooling, ie if people are made to 'keep their place' outside modern employment, their use for schooling will be correspondingly limited. In other words, perceptions of the opportunities for social and economic mobility do seem to be a factor in the demand for schooling.

Suppose the research suggested that employers really had little justification for using different 
levels of scholastic attainment to select employees. Suppose too if suggested that the employers' practices really did affect good education adversely. What alternatives might there be for rationing access to modern jobs? An obvious suggestion is aptitude tests (always supposing that they could be devised), which do not depend on what is learned in school. To the public, performance on such tests would appear to depend on 'natural ability' rather than on hard work in school. So they might offend a public value that hard work should be rewarded. Secondly, they might destroy all motivation to learn in school. Accordingly, a further objective of the research was to discover what people thought was the major factor in scholastic success and how they would react to ideas such as aptitude tests or random selection.

Unger shows that in the city schools of China, when hard work was seen as leading nowhere, hard work declined. In Ghana and Mexico, the majority of parents judged that hard work was the most important element in a child's performance at school, and seemed to feel that aptitude tests, though helpful, might be unfair. Children who worked hard in school were felt to deserve something more than those who had not. Selection by aptitude tests alone, (and even more by any kind of random method), would probably be opposed by parents and might well lead to a decline both in the motivation to learn and in the demand for schooling. Hence, any attempts to alter the bases of selection for employment would need to include a component for ensuring that the public understood and accepted what was being attempted.

These questions and the answers-partial and incomplete as they are-set out in the articles which follow, are important to economic, manpower and education planners. They are of interest also to academic educationists and economists of education. For they involve the four strands of theoretical explanation, which have been put forward to account for the generally observed correlation between levels of scholastic education and levels of earnings. The first-and most influential on policies of educational expenditure -is that learning in schools and universities enhances a person's productive capacities more effectively than learning in other situations, such as the workplace. This view has come to be associated with the idea of human capital.

A second line of explanation is the screening hypothesis. It suggests that schooling does not so much develop a person's abilities as merely identify them: those who are able to continue longest at school are also found to be more able to undertake the more demanding jobs. More and more schooling would be simply finer and finer sieving. The corollary of course would be that the more widely schooling is available, the more schooling employers would need to demand in order to preserve the sieving or screening effect.

A third explanation suggests that employers are indeed using the school and university as sieves. However, what is being sorted out is not ability to undertake jobs of varying responsibility, so much as social background compatible with those already employed at a given level of responsibility and remuneration. Schooling after all is scarce and expensive and tends accordingly to be utilised much more by the better off social classes who already predominate among the better paying jobs. Recruitment by schooling then is merely one means of legitimating and reproducing a social class structure.

The fourth hypothesis acknowledges that the public demand for schooling may indeed be a function of the employers' demand for scholastic qualifications. Nevertheless, this demand is not derived from the actual tasks to be done or careers to be followed. Rather, it is an effect of the available supply of the schooled. Employers tend to use more schooled people merely because they happen to be available. That is, scholastic certificates are largely a convenient and by no means necessary means for rationing access to the competition for jobs.

The findings of the research into qualifications and selection tend to undermine the first and most popular explanation, and to lend strength to the other three. A case has been at least laid for moving to create fresh ways of developing productive manpower and of selecting people for modern jobs.

\section{Acknowledgements}

To carry out research in seven countries almost simultaneously is of course impossible without substantial and generous support in funds. The Commonwealth Secretariat Youth Programme, the Economic and Scientific Committee on Overseas Research of the then British Ministry of Overseas Development, the Ford Foundation, the Nuffield Foundation, the Swedish International Development Authority and the Swedish Agency for Research Cooperation with Developing Countries all in varying degrees made the studies possible. Quite apart from the money involved, 
their willingness to assist in refining methodology and to keep their procedures as flexible as the objectives of the research needed, has been of great value.

Further, the research depended on the collaboration of a number of academic and research institutions. They are:

-in Ghana, the Centre for Development Studies and the Department of Sociology at the University of Cape Coast;

-in Mexico, the Centre for Educational Studies, the National Institute for Labour Studies and the National University;

-in Sri Lanka, the Ministry of Education and the Ministry of Labour's National Institute of Business Management;

-in Sweden, the Institute for International Education, University of Stockholm.

The Institute of Development Studies is thus in the debt of sister institutions elsewhere and is grateful to them for the help they provided in the forms of researchers, data and facilities.

Finally, we offer thanks to those who agreed to comment on the research and its findings for this Bulletin. We had hoped to harvest a wider range of opinion but found that many fellow researchers were too pressed to be able to accept our invitation. We are doubly grateful, therefore, to those who made the time to read our reports and to write down their assessments. We invited sharp comments and have got some. If the readers of this Bulletin are stimulated to send in others, they will be studied with equal interest.

J.O. 